\title{
Usefulness of the clip-and-snare method using the pre-looping technique for endoscopic submucosal dissection of gastric neoplasia: a randomized controlled trial
}

\section{Kenkei Hasatania , Naohiro Yoshida ${ }^{b}$, Hiroyuki Aoyagi ${ }^{a}$, Manami Utsunomiyaa,b, Yoshihide Naito ${ }^{a}$, Yutaka Matanoc, Kei Tominagad, Yohei Waseda', Hisashi Doyamab}

Fukui Prefectural Hospital, Fukui-shi, Fukui; Ishikawa Prefectural Central Hospital, Kanazawa-shi; Komatsu Municipal Hospital, Komatsu-shi, Ishikawa; Kaga Medical Center, Kaga-shi, Ishikawa; Asanogawa General Hospital, Kanazawashi, Ishikawa, Japan

\section{Abstract}

a'Department of Gastroenterology, Fukui Prefectural Hospital, Fukuishi, Fukui (Kenkei Hasatani, Hiroyuki Aoyagi, Manami Utsunomiya, Yoshihide Naito); bepartment of Gastroenterology, Ishikawa Prefectural Central Hospital, Kanazawa-shi, Ishikawa (Naohiro Yoshida, Manami Utsunomiya, Hisashi Doyama); 'Department of Internal Medicine, Komatsu Municipal Hospital, Komatsu-shi, Ishikawa (Yutaka Matano); dDepartment of Internal Medicine, Kaga Medical Center, Kaga-shi, Ishikawa (Kei Tominaga); e Department of Internal Medicine, Asanogawa General Hospital, Kanazawa-shi, Ishikawa (Yohei Waseda), Japan

Conflict of Interest: None

Correspondence to: Kenkei Hasatani, Department of Gastroenterology, Fukui Prefectural Hospital, Fukui-shi, Fukui 910-8526, Japan, e-mail: hasatani9@yahoo.co.jp

Received 31 July 2021; accepted 12 October 2021; published online 6 December 2021

DOI: https://doi.org/10.20524/aog.2021.0679

\section{Introduction}

Endoscopic submucosal dissection (ESD) has been established and widely accepted as the standard treatment for early gastric cancer, with an extremely low probability of lymph node metastasis [1-3]. However, ESD is a time-consuming procedure. In addition, it is associated with relatively high rates of complications, including perforation and delayed bleeding. Furthermore, considerable expertise is required for accurate recognition of the incision line in the submucosal layer during ESD. Several traction methods have been reported to facilitate ESD by enabling appropriate identification of the incision line in the submucosal layer $[4,5]$.

Recent studies have reported the effectiveness of the traction method using a clip and dental floss during gastric ESD [6,7]. While this method has been successfully used for difficult cases, owing to the availability of the tools and its high versatility, its limitations 
include limited tractional direction and difficulty in controlling the traction strength. In addition, a prospective study of this method did not demonstrate shortening of the procedure time [7].

The clip-and-snare method (CSM) is an alternative method that overcomes these limitations, where tension is applied to the lesion by tightening a clip attached to its edge using a scope and an independent snare $[8,9]$. Early reports indicated that forceps were used to guide the snare to the clip attached to the edge of the lesion. This method is considered technically difficult, depending on the location of the lesion, particularly in the upper third of the stomach. This leads to prolonged procedure times and decreased versatility. The CSM using the pre-looping technique (PLT), developed by Yoshida et al [10], has been reported to guide the snare easily and safely, thus shortening the ESD procedure time compared to the conventional ESD method. However, that study had some limitations due to its single-center, retrospective design, including a small sample size, the use of a single type of excision device, and no consideration of the operators' experience level. Therefore, in this multicenter, randomized controlled trial, we aimed to assess the efficacy of CSM-PLT in gastric ESD using a large sample size.

\section{Patients and methods}

\section{Study design}

This study was designed as a randomized, controlled trial conducted at 5 general hospitals in Japan. All procedures performed in studies involving human subjects were in accordance with the ethical standards of the responsible committee on human experimentation (institutional and national) and with the Helsinki Declaration of 1975, as revised in 2000. The study protocol was approved by the Institutional Review Board of each participating hospital. Written informed consent was obtained from all patients before enrollment. The trial was registered with the University Hospital Medical Network Clinical Trials Registry (No. UMIN 000027115).

\section{Patients and randomization}

Eligible patients included those aged $>20$ years who had been histologically diagnosed with gastric adenoma or carcinoma with absolute or expanded indications for ESD according to the Japanese gastric cancer treatment guidelines [11], and who had an Eastern Cooperative Oncology Group performance status of 0-2. The exclusion criteria were as follows: active infection, severe mental disorder, severe respiratory failure, severe cardiac failure, and pregnancy.

Enrolled patients were randomly assigned to the conventional ESD or ESD with CSM-PLT groups. At the time of randomization, the operator faxed the case registration form containing information regarding the allocation factors (operator experience, tumor location, tumor size, and excision device) to the Innovative Clinical Research Center of Kanazawa
University. Allocation was performed using the biased-coin minimization method, and the operator was notified of the allocation result via fax before treatment.

\section{Conventional ESD and CSM-PLT procedures}

ESD was performed using a single-channel endoscope (GIF-Q260J; Olympus Medical Systems, Tokyo, Japan) or a double-channel endoscope (GIF-2TQ260M; Olympus Medical Systems) with a disposable transparent cap (D-201-11804 or D-201-13404; Olympus Medical Systems). Excision devices applied in the registration included partially insulated types, such as the IT knife 2 (KD-611L; Olympus Medical Systems), and non-insulated types (needle-type knife), which included the flush knife (DK2618JN10-30; Fujifilm Medical Systems, Tokyo, Japan), flush knife-BT (DK2618JB; Fujifilm Medical Systems), dual knife (KD-650L; Olympus Medical Systems), hook knife (KD-620LR; Olympus Medical Systems), needle knife (KD-1L-1; Olympus Medical Systems), and flex knife (KD-630L; Olympus Medical Systems). These devices were used for circumferential incision and submucosal dissection. For bleeding during the ESD procedure, endoscopic hemostasis was achieved using a Coagrasper (FD-410LR/FD412-LR; Olympus Medical Systems) or radical jaw (M00515031; Boston Scientific, Tokyo, Japan).

In the CSM-PLT group, the procedure was performed using the method described in a previous report [10]. The CSM-PLT technique and actual endoscopic view are shown in Fig. 1 and 2, respectively. After circumferential incision, the endoscope was withdrawn once to pre-loop a snare (SD-221U-25; Olympus Medical Systems) outside the endoscope (Fig. 1A). The endoscope was then reinserted into the lesion with a snare, and a clip (HX-610-090; Olympus Medical Systems) was inserted through the working channel of the endoscope using a reusable clip deployment device (EZ CLIP; Olympus Medical Systems). The clip was used to grasp the lesion edge (oral side of the lesion if the endoscope was in the straight position and anal side if it was in the retroflex position). This was done carefully to ensure that the clip did not detach completely from the deployment device (Fig. 1B). The pre-looped snare was then loosened and moved along the forceps to the clip (Fig. 1C). The clip was tightened with the snare and finally released from the deployment device (Fig. 1D). Subsequently, appropriate traction to the lesion was achieved using the clip and snare, independently of the endoscope (Fig. 1E). The moderate rigidity of the snare allows the operator to push, as well as pull, the lesion (Fig. 2A-F). In order to maintain the tension of the snare, clothespins can be used to conveniently fix the slider of the snare.

An operator change from novice to expert was permitted if the expert judged that there was a high risk of potentially serious complications due to prolonged procedure time or intraoperative complications. Moreover, even in the conventional ESD group, the use of CSM-PLT was permitted if the expert judged that the procedure would be technically difficult to complete if conventional ESD was continued.

All ESD procedures were performed under unconscious sedation without intubation using midazolam, pentazocine, 


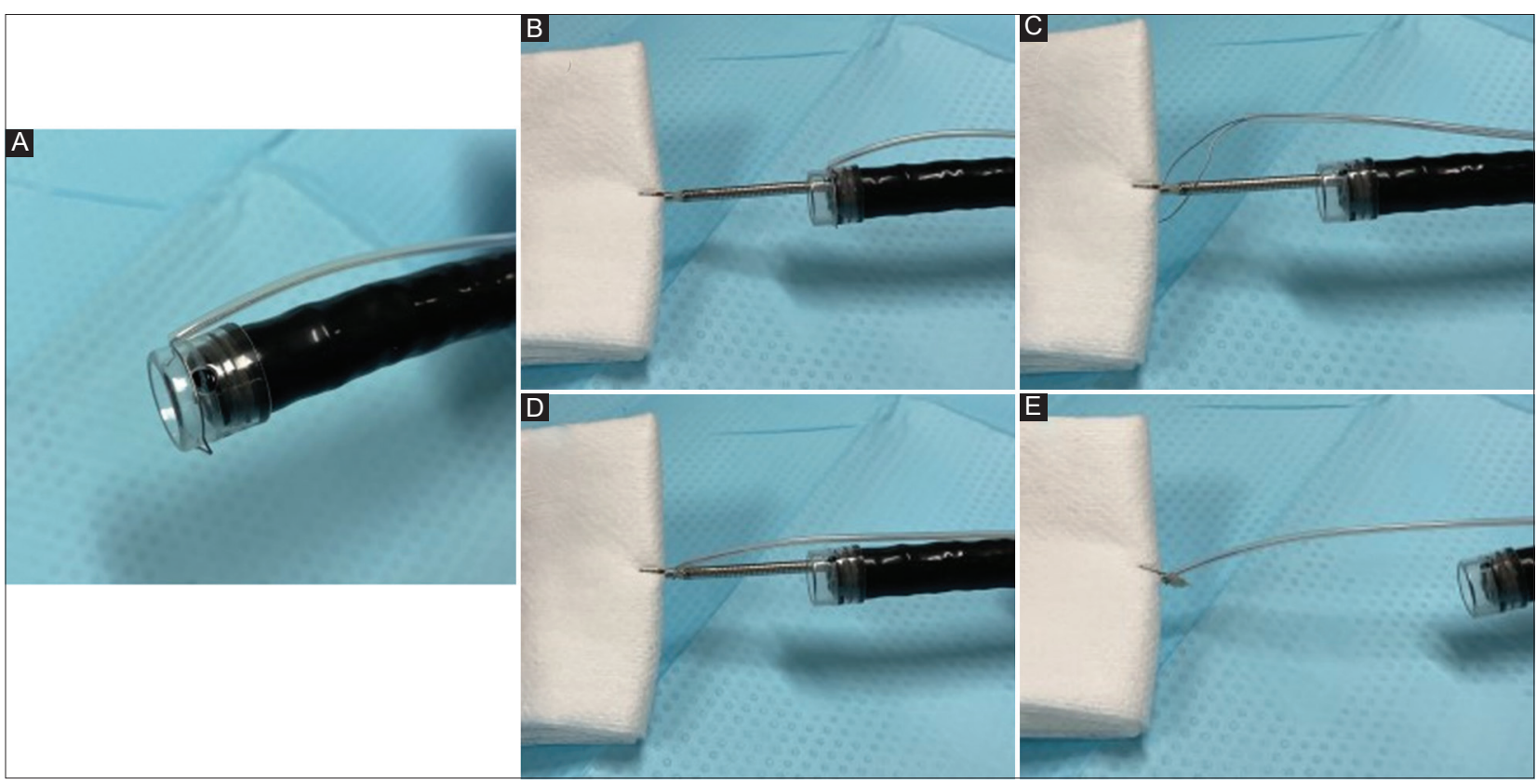

Figure 1 The clip-and-snare method using the pre-looping technique. (A) A transparent cap is tightened with a snare from the outside of the endoscope. (B) The clip is inserted with forceps and used to grasp the edge of the lesion. (C) The snare is loosened and moved along the forceps to the clip. (D) The clip is tightened by the snare. (E) The clip is released from the forceps, following which the appropriate traction can be obtained independently of the endoscope

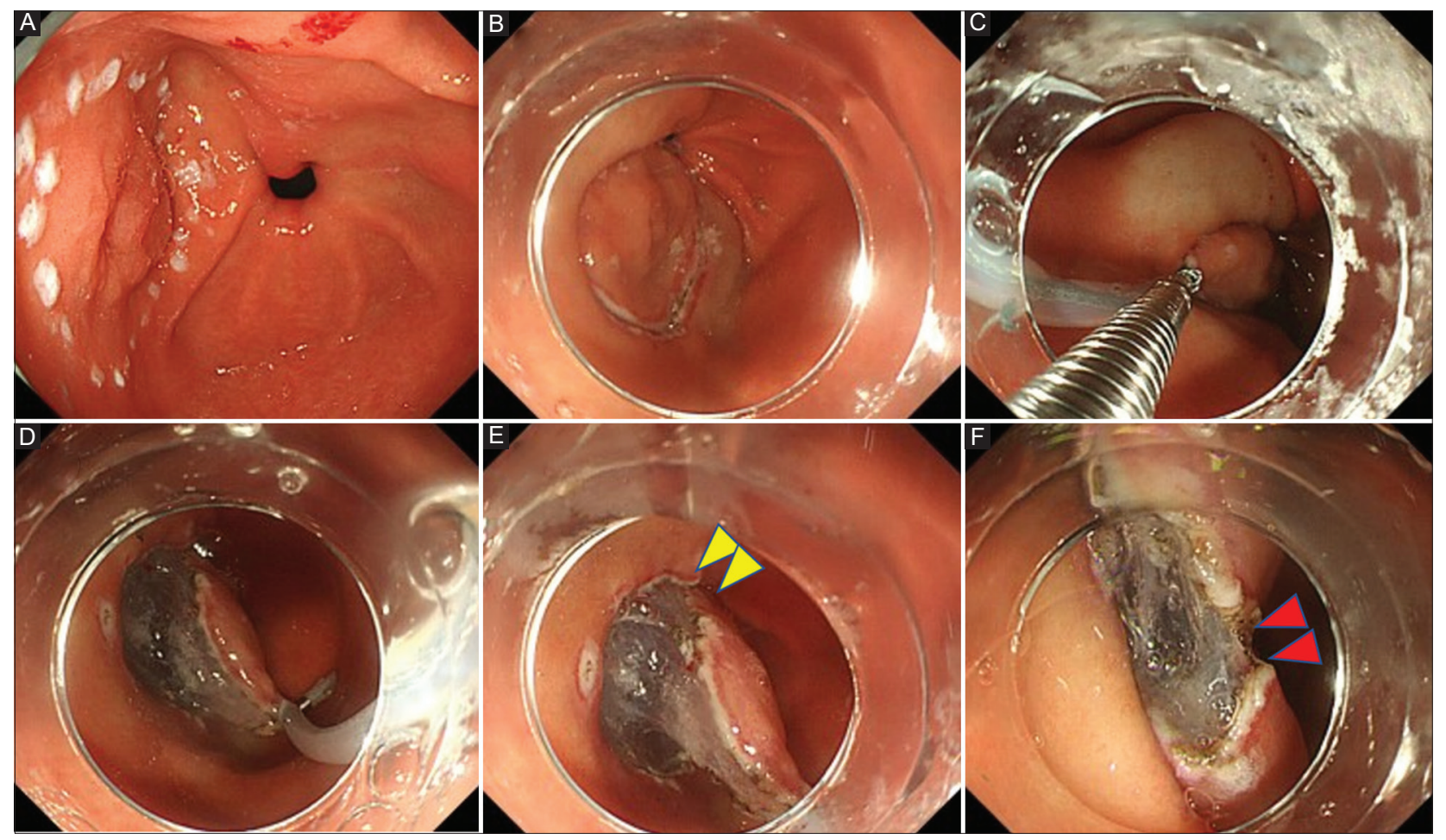

Figure 2 Endoscopic view showing the clip-and-snare method using the pre-looping technique. (A) After marking outside the elevated lesion in the anterior wall of the lower third of the stomach. (B) After circumferential incision. (C) A clip holding the mucosal flap tightened by the snare, which had been pre-looped over the endoscope. (D) A clip released from the clip deployment device. (E) Pushing the snare: appropriate tension and good visualization were obtained for submucosal dissection in the lesser curvature side of the lesion (yellow arrowheads). (F) Pulling the snare: appropriate tension and good visualization were obtained in the greater curvature side of the lesion (red arrow heads) 
dexmedetomidine hydrochloride, and propofol for adequate sedation. During the perioperative period of ESD, antithrombotic drugs were suspended, in accordance with the guidelines for gastroenterological endoscopy in patients undergoing antithrombotic treatment $[12,13]$. The histological evaluation was based on the Japanese classification of gastric carcinoma [14].

\section{Definitions}

Procedure time was defined as the time from the start of injection to the submucosa until the completion of lesion dissection. The lesion dissection time was defined as the time from the end of the circumferential incision to the completion of lesion dissection.

For the analysis, operators were divided into the following 2 categories: novices and experts. A novice was defined as an endoscopist with ESD experience of $<50$ procedures, whereas an expert was defined as an endoscopist with ESD experience of $\geq 50$ procedures. En bloc resection was defined as resection of the lesion in a single piece. R0 resection was defined as en bloc resection with tumor cell-free lateral and vertical margins. The frequency of hemostasis included not only active bleeding but also pre-coagulation of the vessel at risk of bleeding. Perforation was defined as endoscopic visualization of the extra-serosal tissue during the procedure or observation of free air on abdominal X-ray or computed tomography after the procedure. Delayed bleeding was defined as overt bleeding requiring endoscopic hemostasis or a decrease of $>2 \mathrm{~g} / \mathrm{dL}$ in hemoglobin levels after ESD.

\section{Outcomes}

The primary endpoint of this study was ESD procedure time. The secondary endpoints, according to allocation factors, were as follows: procedure time according to operator experience, tumor location, tumor size, and excision device. Other secondary endpoints included lesion dissection time, procedure time for lesions with ulcerative findings, frequency of endoscopic hemostasis, total time to hemostasis, en bloc resection rate, $\mathrm{R} 0$ resection rate, endoscopic curative resection rate, and incidence of adverse events, including perforation and delayed bleeding.

\section{Sample size}

The sample size was estimated based on our previous retrospective study [10]. The ESD procedure times for conventional ESD and ESD with CSM-PLT were 59.5 and $38.5 \mathrm{~min}$, respectively. For CSM-PLT, the clinically meaningful reduction time was set to $10 \mathrm{~min}$. The required number of patients was calculated based on an alpha error of 0.05 and a statistical power of $80 \%$, resulting in 194 patients in one group. Assuming a dropout rate of $3 \%$, the total number of patients required was 400 .

\section{Statistical analysis}

All statistical analyses were performed using methods determined before the trial. We analyzed the outcome data by performing a per-protocol analysis. Patients who met the following criteria were excluded, even after randomization: 1) ineligible based on enrollment criteria; 2) ESD not performed; 3) conversion from conventional ESD to ESD with CSM-PLT; and 4) $>30$ min of handover time to an expert during an ESD procedure performed by a novice. For comparisons between the 2 groups, continuous variables were expressed as the mean \pm standard deviation and analyzed using the Student's $t$-test, whereas categorical variables were expressed as the number and percentage and analyzed using the chi-square test. $\mathrm{P}<0.05$ was considered statistically significant. All analyses were conducted using EZR (version 1.52; Saitama Medical Center, Jichi Medical University, Saitama, Japan), a graphical user interface for R (version 4.02; The R Foundation for Statistical Computing, Vienna, Austria).

\section{Results}

\section{Patient and tumor characteristics}

Altogether, 402 patients were enrolled between July 2017 and February 2020; of these, 202 and 200 were randomly assigned to the conventional ESD and CSM-PLT groups, respectively. In the conventional ESD group, an expert took over the procedure for a duration of $>30$ min for 2 lesions; the procedure was converted to ESD with CSM-PLT to overcome technical difficulties for 4 lesions; ESD was not performed for one lesion; an unregistered incision knife was used for 1 lesion; a change to an unregistered operator was noted for 1 lesion; and cancer of another organ was noted for 1 lesion. In the CSMPLT group, an expert took over the procedure for a duration of $>30 \mathrm{~min}$ for 11 lesions and ESD was not performed for 3 lesions. After excluding these cases, 378 patients were finally included in the per-protocol analysis (Fig. 3). The baseline characteristics of each treatment group are shown in Table 1. There were no significant differences in these characteristics between the 2 groups.

\section{Primary endpoint and subgroup analysis}

The mean procedure times were 69.7 and $58.0 \mathrm{~min}$ for the conventional ESD and CSM-PLT groups, respectively, indicating that the procedure was significantly shorter in the CSM-PLT group $(\mathrm{P}=0.009)$. The mean dissection time was significantly faster in the CSM-PLT group than in the conventional ESD group ( $\mathrm{P}=0.008)$. All lesions were resected en bloc. The R0 resection rate tended to be higher in the CSMPLT group than in the conventional ESD group $(\mathrm{P}=0.09)$. No significant differences in the frequency of hemostasis or time to hemostasis were observed between the 2 groups. Perforation 


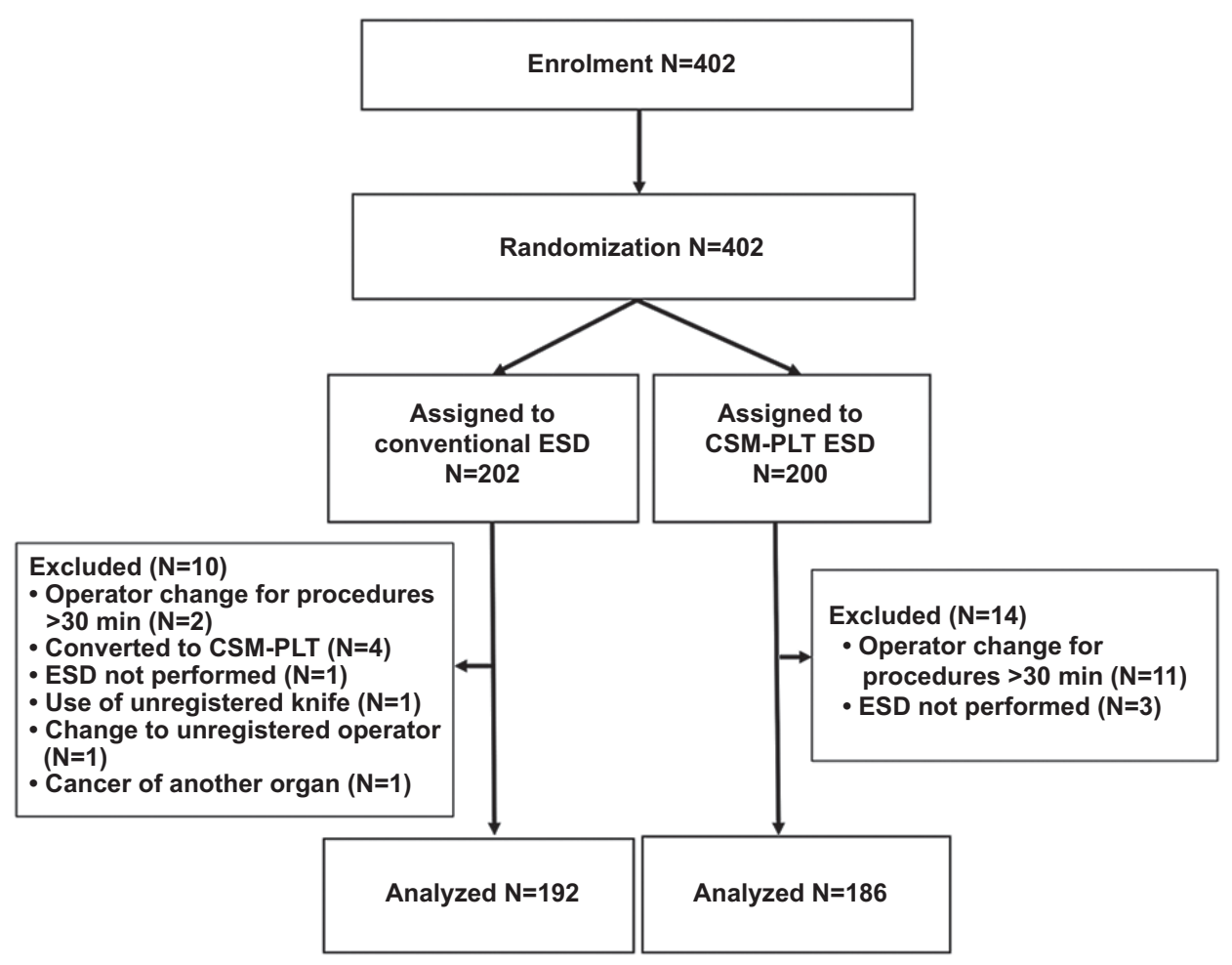

Figure 3 Study flow diagram

ESD, endoscopic submucosal dissection; CSM-PLT, clip-and-snare method using pre-looping technique

was observed in 4 lesions in the conventional ESD group and in 1 lesion in the CSM-PLT group. All cases with perforation were treated conservatively, and no case required emergency surgery. Delayed bleeding was observed in 8 and 9 lesions in the conventional ESD and CSM-PLT groups, respectively. There were no significant differences in complications between the 2 groups (Table 2).

Table 3 shows the results of the subgroup analysis of procedure time according to operator experience, tumor size, tumor location, excision device, and the presence of ulcerative findings. The mean procedure time was significantly shorter in the novice $(\mathrm{P}=0.04)$, tumor size $\leq 20 \mathrm{~mm}(\mathrm{P}=0.02)$, and IT knife $(\mathrm{P}=0.045)$ groups. The mean preparation time for CSM-PLT was $2.3 \mathrm{~min}$.

\section{Discussion}

In this study, the CSM-PLT group exhibited a significantly shorter procedure time than the conventional ESD group (58.0 vs. $69.7 \mathrm{~min} ; \mathrm{P}=0.009$ ). To our knowledge, this is the first large multicenter, randomized controlled trial demonstrating the efficacy of this traction method in terms of procedure time for gastric ESD.

All lesions were resected en bloc in patients undergoing the CSM-PLT procedure, which tended to have a higher R0 resection rate than conventional ESD. No significant differences were observed between the 2 groups in terms of complications, including perforation and delayed bleeding. In the subgroup analysis, the procedure time for novices was significantly shorter in the CSMPLT group than in the conventional ESD group. Therefore, these results suggest that CSM-PLT is a safe traction method for gastric ESD, with no increase in the risk of complications.

Over the years, several traction methods have been reported to facilitate ESD, such as the external grasping forceps [15], double-scope [16], and magnetic anchor [17] methods. However, they are not widely accepted because of their low availability. Although a spring-and-loop method utilizing a clip has been reported to reduce ESD procedure time [18], that study had some limitations, including being single-centered with a relatively small sample size and the procedure being performed by a single expert operator. Hence, a randomized prospective study targeting multiple operators at multiple centers is to be desired.

The clip-and-line method $[6,7,19]$ is widely used, owing to its simplicity and accessibility. Yoshida et al [7] conducted a large-scale multicenter, randomized controlled trial of the use of dental floss, reporting no significant decrease in the total procedure time, considered the primary endpoint.

The CSM-PLT method offers some advantages as a traction method for gastric ESD. The PLT allows for easier and faster traction of the lesions. In our study, it took only $2.3 \mathrm{~min}$ on average to withdraw the endoscope, grip the clip with a snare, and complete the CSM. Given that the pulling force is adjustable, this method allows for traction in the direction of both the oral and anal sides by pulling or pushing the snare. Other advantages include the ease of separating the clip and snare by loosening the 
Table 1 Baseline characteristics of the study subjects

\begin{tabular}{|c|c|c|c|}
\hline Characteristics & $\begin{array}{c}\text { Conventional } \\
\text { ESD } \\
(n=192)\end{array}$ & $\begin{array}{c}\text { ESD with } \\
\text { CSM-PLT } \\
(n=186)\end{array}$ & P-value \\
\hline Age, years & $72.2 \pm 8.5$ & $71.0 \pm 9.2$ & 0.17 \\
\hline $\begin{array}{l}\text { Sex } \\
\quad \text { Male } \\
\text { Female }\end{array}$ & $\begin{array}{c}151(78.6) \\
41(21.4)\end{array}$ & $\begin{array}{c}144(77.4) \\
42(22.6)\end{array}$ & 0.77 \\
\hline $\begin{array}{l}\text { Operator experience } \\
\text { Expert } \\
\text { Novice }\end{array}$ & $\begin{array}{c}108(56.2) \\
84(43.8)\end{array}$ & $\begin{array}{c}114(61.3) \\
72(38.7)\end{array}$ & 0.32 \\
\hline Tumor size, $\mathrm{mm}$ & $13.8 \pm 9.5$ & $13.2 \pm 8.8$ & 0.57 \\
\hline $\begin{array}{l}\text { Macroscopic type } \\
\text { Elevated } \\
\text { Flat } \\
\text { Depressed }\end{array}$ & $\begin{array}{c}72(37.5) \\
6(3.1) \\
114(59.4)\end{array}$ & $\begin{array}{c}73(39.2) \\
7(3.8) \\
106(57.0)\end{array}$ & 0.19 \\
\hline Ulcer findings (positive) & $11(5.7)$ & $8(4.3)$ & 0.53 \\
\hline $\begin{array}{l}\text { Histology } \\
\text { Adenoma } \\
\text { Differentiated } \\
\text { carcinoma } \\
\text { Undifferentiated } \\
\text { carcinoma } \\
\text { Others }\end{array}$ & $\begin{array}{c}18(9.4) \\
159(82.8) \\
13(6.8) \\
2(1.0)\end{array}$ & $\begin{array}{c}19(10.2) \\
157(84.4) \\
7(3.8) \\
3(1.6)\end{array}$ & 0.58 \\
\hline $\begin{array}{l}\text { Tumor depth } \\
\text { Intramucosal } \\
\text { Submucosal }\end{array}$ & $\begin{array}{c}171(89.1) \\
21(10.9)\end{array}$ & $\begin{array}{c}172(92.5) \\
14(7.5)\end{array}$ & 0.25 \\
\hline $\begin{array}{l}\text { Tumor location } \\
\mathrm{U} / \mathrm{M} \text {, lesser curvature } \\
\mathrm{U} / \mathrm{M} \text {, greater curvature } \\
\mathrm{U} / \mathrm{M} \text {, anterior wall } \\
\mathrm{U} / \mathrm{M} \text {, posterior wall } \\
\mathrm{L} \text {, lesser curvature } \\
\mathrm{L} \text {, greater curvature } \\
\mathrm{L} \text {, anterior wall } \\
\mathrm{L} \text {, posterior wall }\end{array}$ & $\begin{array}{l}43(22.4) \\
29(15.1) \\
17(8.9) \\
24(12.5) \\
32(16.7) \\
23(12.0) \\
12(6.3) \\
12(6.3)\end{array}$ & $\begin{array}{l}54(29.0) \\
22(11.8) \\
10(5.4) \\
23(12.4) \\
26(14.0) \\
22(11.8) \\
13(7.0) \\
16(8.6)\end{array}$ & 0.63 \\
\hline
\end{tabular}

Values are represented as mean \pm standard deviation or as number (percentage)

ESD, endoscopic submucosal dissection; CSM-PLT, clip-and-snare method using pre-looping technique; $U$, upper third, $M$, middle third, $L$, lower third

snare's grip and the ease of changing the traction points. These advantages seem to have contributed greatly to the shortening of the procedure time observed in this study.

In this study, a higher $\mathrm{R} 0$ resection rate was observed in the CSM-PLT group, although there was no difference between the 2 groups in the en bloc resection rate. From pathological examinations, 6 lesions with vertical margin positive or inconclusive were observed in the conventional ESD group, compared to only 2 lesions in the CSM-PLT group (data not shown). Moreover, perforation occurred in 4 lesions in the conventional ESD group, compared to only 1 lesion in the CSM-PLT group. CSM-PLT improved the visibility of the submucosal layer and facilitated appropriate and safe incision.

Regarding procedure time by tumor location, a prospective trial of the clip-and-line method [7] demonstrated a significant decrease in the procedure time for lesions located in the greater
Table 2 Clinical outcomes of ESD for gastric neoplasm

\begin{tabular}{|c|c|c|c|}
\hline Outcome & $\begin{array}{c}\text { Conventional } \\
\text { ESD } \\
(n=192)\end{array}$ & $\begin{array}{c}\text { ESD with } \\
\text { CSM-PLT } \\
(n=186)\end{array}$ & $\mathrm{P}$-value \\
\hline $\begin{array}{l}\text { Total procedure time, } \\
\text { min }\end{array}$ & $69.7 \pm 45.1$ & $58.0 \pm 41.0$ & 0.009 \\
\hline Specimen size, $\mathrm{mm}$ & $35.4 \pm 10.3$ & $35.9 \pm 11.5$ & 0.63 \\
\hline Dissection time, min & $49.4 \pm 37.2$ & $39.7 \pm 33.2$ & 0.008 \\
\hline $\begin{array}{l}\text { Frequency of } \\
\text { hemostasis }\end{array}$ & $3.7 \pm 4.2$ & $3.4 \pm 5.1$ & 0.50 \\
\hline $\begin{array}{l}\text { Time to hemostasis, } \\
\text { min }\end{array}$ & $5.8 \pm 7.3$ & $5.0 \pm 8.3$ & 0.35 \\
\hline En bloc resection & $192(100)$ & $186(100)$ & $>0.99$ \\
\hline Complete resection & $183(95.3)$ & $183(98.4)$ & 0.09 \\
\hline \multicolumn{4}{|l|}{ Adverse events } \\
\hline Perforation & $4(2.1)$ & $1(0.5)$ & 0.19 \\
\hline Delayed bleeding & $8(4.2)$ & $9(3.2)$ & 0.63 \\
\hline
\end{tabular}

Values are represented as mean \pm standard deviation or as number (percentage)

ESD, endoscopic submucosal dissection; CSM-PLT, clip-and-snare method using pre-looping technique

Table 3 Procedure time of ESD according to operator, device, and tumor characteristics

\begin{tabular}{lccc}
\hline Subgrouping criterion & $\begin{array}{c}\text { Conventional } \\
\text { ESD }\end{array}$ & $\begin{array}{c}\text { ESD with } \\
\text { CSM-PLT }\end{array}$ & P-value \\
\hline Operator & & & \\
$\quad$ Expert & $69.6 \pm 47.6$ & $58.9 \pm 44.7$ & 0.09 \\
Novice & $69.7 \pm 42.0$ & $56.6 \pm 34.5$ & 0.04 \\
Tumor size & & & \\
$\leq 20 \mathrm{~mm}(\mathrm{n}=315)$ & $62.6 \pm 38.9$ & $52.7 \pm 38.6$ & 0.02 \\
$>20 \mathrm{~mm}(\mathrm{n}=63)$ & $102.4 \pm 56.8$ & $86.7 \pm 42.7$ & 0.23 \\
Device & & & \\
IT2 & $56.6 \pm 33.6$ & $46.9 \pm 36.7$ & 0.045 \\
Needle type & $86.1 \pm 52.0$ & $72.5 \pm 42.1$ & 0.07 \\
Preparation time for CSM & $\mathrm{N} / \mathrm{A}$ & $2.3 \pm 1.3$ & $\mathrm{~N} / \mathrm{A}$ \\
Ulcer finding (positive) & $110.9 \pm 31.1$ & $91.3 \pm 38.9$ & 0.23 \\
Tumor location & & & \\
U/M lesser curvature & $70.7 \pm 33.8$ & $73.4 \pm 53.2$ & 0.78 \\
U/M greater curvature & $69.3 \pm 40.6$ & $49.0 \pm 31.3$ & 0.06 \\
U/M anterior wall & $74.9 \pm 56.5$ & $68.5 \pm 34.6$ & 0.75 \\
U/M posterior wall & $103.7 \pm 55.1$ & $74.7 \pm 43.2$ & 0.051 \\
L lesser curvature & $68.2 \pm 43.5$ & $52.0 \pm 31.1$ & 0.12 \\
L greater curvature & $41.6 \pm 25.4$ & $37.4 \pm 16.0$ & 0.52 \\
L anterior wall & $62.0 \pm 50.3$ & $34.4 \pm 15.2$ & 0.07 \\
L posterior wall & $56.9 \pm 46.1$ & $45.7 \pm 31.1$ & 0.45 \\
\hline
\end{tabular}

Values are represented as mean \pm standard deviation

N/A not applicable; ESD, endoscopic submucosal dissection; CSM-PLT, clipand-snare method using pre-looping technique; $U$, upper third, $M$, middle third, L, lower third

curvature of the upper or middle stomach. In this study, although there were no areas with significant differences, a shorter procedure time was observed for the greater curvature $(\mathrm{P}=0.06)$, posterior wall $(\mathrm{P}=0.051)$ of the upper or middle third, 
and anterior wall of the lower third $(\mathrm{P}=0.07)$ of the stomach. Previous studies have reported that lesions in the upper or middle third or around the greater curvature of the stomach require a longer procedure time, indicating that these locations are factors affecting ESD procedure time [20,21]. Using a traction method in these areas is likely to facilitate submucosal resection, with the lesion being pulled vertically and the mucosa being lifted from the submucosa, thus ensuring appropriate visibility.

Although there are currently no reports of the efficacy of traction methods in the lower third of the stomach, it is possible that CSM-PLT led to a shorter procedure time by allowing the application of tension in the direction of both the anal and oral sides via pushing and pulling, thus pushing the lesion in the anterior wall of the lower third of the stomach in a vertical direction and providing a clearer view.

To ensure that ESD may be performed safely on a global scale, it is important to determine whether methods are effective in the hands of less-experienced operators. With a low selfcompletion rate [22] and a higher rate of complications, such as delayed bleeding [23], among less-experienced operators, achieving consistency in ESD skills requires some level of experience $[24,25]$. However, despite the widespread use of gastric ESD in western countries, the overall number of gastric ESDs performed is small in some regions [26]; hence, it is essential to develop a method also effective for less experienced operators so that ESD may become more popular globally.

In this study, the subgroup analysis according to the operators' experience level indicated that these methods may be useful for shortening the procedure time for novices. Previous studies that evaluated the effects of operator experience on gastric ESD outcomes showed that using traction methods led to a shorter procedure time for experts [27], and a tendency toward a shorter procedure time for novices [7]. However, to our knowledge, no previous studies have reported statistically significant differences for novices.

In this study, we also included the excision device (IT knife or needle-knife) as an allocation factor in the randomization process to assess differences in the efficacy of CSM-PLT. Although the partially insulated knife can excise the submucosal tissue faster than the needle-type knife [28,29], the compatibility between the type of knife and the traction method was unknown. Since the needle-type knife allows for traction using an endoscope attachment, it initially appeared that it may not be necessary to combine this type of knife with a traction method. However, a shorter procedure time was observed using both excision devices. This result might confirm the efficacy of CSM-PLT, regardless of the excision device used.

Our study had some limitations. First, due to the nature of the trial, the operators were not blinded to the allocated treatment group, as they knew the allocation results beforehand. Second, the 5 hospitals participating in this study had previous experience of CSM-PLT before the start of the trial. Therefore, the CSM-PLT learning curve was not taken into consideration, and this may have affected the results. Third, we evaluated the efficacy of different cutting devices using only IT knives or needle-type knives, not grasping-type scissor forceps, which have often been used recently. Fourth, there were 2 cases in which an expert took over the procedure being performed by a novice for $>30 \mathrm{~min}$ in the conventional ESD group, and 11 such cases in the CSM-PLT group. Although the reasons for this gap in the number of handovers remain unclear, the CSM-PLT group might have included more technically difficult cases than conventional group at the time of randomization. Although we believe that we could perform an analysis that reduced this unevenness by excluding these cases, we cannot deny that this had become a cause of selection bias. Furthermore, as novices performed the procedure under the supervision of experts, the exact evaluation of novice procedure time and complications was not possible in cases where an expert took over. Further prospective studies are necessary to evaluate these aspects.

In conclusion, this prospective study demonstrated that incorporating the CSM-PLT method shortened the ESD procedure time. Moreover, CSM-PLT is safe, does not increase complication rates, and is associated with better R0 resection rates than conventional ESD. Further application of this method is expected to contribute to the improved global availability of safe and reliable ESD.

\section{Acknowledgment}

We thank Shizuko Takahara for her significant contribution to the implementation of the study.

\section{Summary Box}

\section{What is already known:}

- The clip-and-snare method (CSM) for endoscopic submucosal dissection (ESD) is technically difficult depending on the location of the lesion, particularly in the upper third of the stomach, leading to prolonged procedure times and decreased versatility

- CSM using the pre-looping technique (PLT) has been reported to guide the snare easily and safely, thus shortening the ESD procedure time compared to conventional ESD

- However, the original study had a small sample size, used a single type of excision device, and did not consider the endoscopists' level of experience, which can influence the ESD procedure

\section{What the new findings are:}

- The procedure time was significantly shorter in the CSM-PLT group than in the conventional ESD group, while the $\mathrm{R} 0$ resection rate tended to be higher in the CSM-PLT group

- No significant differences in complications were observed between the 2 groups 


\section{References}

1. Japanese Gastric Cancer Association. Japanese gastric cancer treatment guidelines 2018 ( $5^{\text {th }}$ edition). Gastric Cancer 2021;24:1-21.

2. Ono H, Yao K, Fujishiro M, et al. Guidelines for endoscopic submucosal dissection and endoscopic mucosal resection for early gastric cancer (second edition). Dig Endosc 2021;33:4-20.

3. Pimentel-Nunes P, Dinis-Ribeiro M, Ponchon T, et al. Endoscopic submucosal dissection: European Society of Gastrointestinal Endoscopy (ESGE) Guideline. Endoscopy 2015;47:829-854.

4. Oyama T. Counter traction makes endoscopic submucosal dissection easier. Clin Endosc 2012;45:375-378.

5. Tsuji K, Yoshida N, Nakanishi H, Takemura K, Yamada S, Doyama H. Recent traction methods for endoscopic submucosal dissection. World J Gastroenterol 2016;22:5917-5926.

6. Suzuki S, Gotoda T, Kobayashi Y, et al. Usefulness of a traction method using dental floss and a hemoclip for gastric endoscopic submucosal dissection: a propensity score matching analysis (with videos). Gastrointest Endosc 2016;83:337-346.

7. Yoshida M, Takizawa K, Suzuki S, et al; CONNECT-G Study Group. Conventional versus traction-assisted endoscopic submucosal dissection for gastric neoplasms: a multicenter, randomized controlled trial (with video). Gastrointest Endosc 2018;87:1231-1240.

8. Yasuda M, Naito Y, Kokura S, Yoshida N, Yoshikawa T. Sa1687 newly-developed ESD (CSL-ESD) for early gastric cancer using convenient and low-cost lifting method (lifting method using clips and snares) for lesions is clinically useful. Gastrointest Endosc 2012;75:AB244.

9. Baldaque-Silva F, Vilas-Boas F, Velosa M, Macedo G. Endoscopic submucosal dissection of gastric lesions using the "Yo-Yo technique". Endoscopy 2013;45:218-221.

10. Yoshida N, Doyama H, Ota R, et al. Effectiveness of clip-andsnare method using pre-looping technique for gastric endoscopic submucosal dissection. World J Gastrointest Endosc 2016;8:451-457.

11. Japanese Gastric Cancer Association. Japanese gastric cancer treatment guidelines 2014 (ver. 4). Gastric Cancer 2017;20:1-19.

12. Fujimoto K, Fujishiro M, Kato M, et al; Japan Gastroenterological Endoscopy Society. Guidelines for gastroenterological endoscopy in patients undergoing antithrombotic treatment. Dig Endosc 2014;26:1-14.

13. Kato M,Uedo N,HokimotoS, etal.Guidelinesforgastroenterological endoscopy in patients undergoing antithrombotic treatment: 2017 appendix on anticoagulants including direct oral anticoagulants. Dig Endosc 2018;30:433-440.

14. Japanese Gastric Cancer Association. Japanese classification of gastric carcinoma: $3^{\text {rd }}$ English edition. Gastric Cancer 2011;14:101-112.

15. Imaeda H, Hosoe N, Ida Y, et al. Novel technique of endoscopic submucosal dissection using an external grasping forceps for superficial gastric neoplasia. Dig Endosc 2009;21:122-127.

16. Higuchi K, Tanabe S, Azuma M, et al. Double-endoscope endoscopic submucosal dissection for the treatment of early gastric cancer accompanied by an ulcer scar (with video). Gastrointest Endosc 2013;78:266-273.

17. Gotoda T, Oda I, Tamakawa K, Ueda H, Kobayashi T, Kakizoe T. Prospective clinical trial of magnetic-anchor-guided endoscopic submucosal dissection for large early gastric cancer (with videos). Gastrointest Endosc 2009;69:10-15.

18. Nagata M, Fujikawa T, Munakata H. Comparing a conventional and a spring-and-loop with clip traction method of endoscopic submucosal dissection for superficial gastric neoplasms: a randomized controlled trial (with videos). Gastrointest Endosc 2021;93:1097-1109.

19. Jeon WJ, You IY, Chae HB, Park SM, Youn SJ. A new technique for gastric endoscopic submucosal dissection: peroral tractionassisted endoscopic submucosal dissection. Gastrointest Endosc 2009;69:29-33.

20. Imagawa A, Okada H, Kawahara Y, et al. Endoscopic submucosal dissection for early gastric cancer: results and degrees of technical difficulty as well as success. Endoscopy 2006;38:987-990.

21. Nagata S, Jin YF, Tomoeda M, et al. Influential factors in procedure time of endoscopic submucosal dissection for gastric cancer with fibrotic change. Dig Endosc 2011;23:296-301.

22. Ono S, Kato M, Nakagawa M, Imai A, Yamamoto K, Shimizu Y. Outcomes and predictive factors of "not self-completion" in gastric endoscopic submucosal dissection for novice operators. Surg Endosc 2013;27:3577-3583.

23. Tsuji Y, Ohata K, Ito T, et al. Risk factors for bleeding after endoscopic submucosal dissection for gastric lesions. World $J$ Gastroenterol 2010;16:2913-2917.

24. Yamamoto Y, Fujisaki J, Ishiyama A, Hirasawa T, Igarashi M. Current status of training for endoscopic submucosal dissection for gastric epithelial neoplasm at Cancer Institute Hospital, Japanese Foundation for Cancer Research, a famous Japanese hospital. Dig Endosc 2012;24(Suppl 1):148-153.

25. Oda I, Odagaki T, Suzuki H, Nonaka S, Yoshinaga S. Learning curve for endoscopic submucosal dissection of early gastric cancer based on trainee experience. Dig Endosc 2012;24(Suppl 1):129-132.

26. Oyama T, Yahagi N, Ponchon T, Kiesslich T, Berr F. How to establish endoscopic submucosal dissection in Western countries. World J Gastroenterol 2015;21:11209-11220.

27. Hashimoto R, Hirasawa D, Iwaki T, et al. Usefulness of the S-O clip for gastric endoscopic submucosal dissection (with video). Surg Endosc 2018;32:908-914.

28. Kanzaki H, Ishihara R, Ohta T, et al. Randomized study of two endo-knives for endoscopic submucosal dissection of esophageal cancer. Am J Gastroenterol 2013;108:1293-1298.

29. Yamashita T, Zeniya A, Otani S. Endoscopic submucosal dissection (ESD) using the needle knife: its superiority to ESD using the insulation-tipped diathermic knife in physicians intending to master ESD. Surg Laparosc Endosc Percutan Tech 2010;20:180-185. 